Int. J. Dev. Biol. 51: 67-77 (2007)

doi: $10.1387 / \mathrm{ijdb} .062216 \mathrm{tt}$

Original Article

\title{
Amniotic fluid induces rapid epithelialization in the experimentally ruptured fetal mouse palate - implications for fetal wound healing
}

\author{
TOSHIYA TAKIGAWA ${ }^{1, *}$ and KOHEI SHIOTA ${ }^{1,2}$ \\ ${ }^{1}$ Department of Anatomy and Developmental Biology and ${ }^{2}$ Congenital Anomaly Research Center, Kyoto University Graduate School of \\ Medicine, Kyoto, Japan
}

\begin{abstract}
Cleft of the secondary palate is one of the most common congenital birth defects in humans. The primary cause of cleft palate formation is a failure of fusion of bilateral palatal shelves, but rupture of the once fused palate has also been suggested to take place in utero. The possibility of post-fusion rupture of the palate in humans has hardly been accepted, mainly because in all the cleft palate cases, the cleft palatal edge is always covered with intact epithelium. To verify whether the intrauterine environment of the fetus plays roles in wound healing when the once fused palate is torn apart, we artificially tore apart fetal mouse palates after fusion and cultivated them in culture medium with or without mouse or human amniotic fluid. We thereby found that the wounded palatal edge became completely covered with flattened epithelium after 36 hours in culture with amniotic fluid, but not in culture without amniotic fluid. Using histological and scanning electron microscopic analyses of the healing process, it was revealed that the epithelium covering the wound was almost exclusively derived from the adjacent nasal epithelium, but not from the oral epithelium. Such actions of amniotic fluid on the fetal wound were never simulated by exogenous epidermal growth factor (EGF), albumin, or both. In addition, the rapid epithelialization induced by amniotic fluid was not prevented by either PD168393 (an inhibitor of the EGF receptor-specific tyrosine kinase) or SB431542 (a specific inhibitor of TGFbeta receptor type I/ALK5). The present study provides new insights into the unique biological actions of amniotic fluid in the repair of injured fetal palate.
\end{abstract}

KEY WORDS: secondary palate, wound healing, epithelialization, amniotic fluid, post-fusion rupture

\section{Introduction}

Non-syndromic cleft of the secondary palate is one of the most common congenital birth defects in humans with an approximate incidence of 1 in 2000 live births (Johnston and Bronsky, 1995). The cause of human cleft palate is still unclear but is assumed to be multi-factorial, involving various genetic and environmental factors (Sperber and Machin, 1994; Johnston and Bronsky, 1995). The formation of the mammalian secondary palate requires several developmental steps, including growth, elevation and midline fusion of the palatal shelves (Ferguson, 1988). Before the midline fusion of the palatal shelves, medial edge epithelial (MEE) cells cover the apical portion of the bilateral shelves. Following contact of the apposed shelves above the tongue, MEE cells form a midline epithelial seam and subsequently disappear to bring about mesenchymal confluence across the bilateral palatal shelves, thereby completing the fusion.

Stark and Ehrmann (1958) stated that disruption at any step before palatal fusion can result in cleft palate, but once the fusion has taken place, the palate would remain fused throughout the subsequent stages of development. On the other hand, Kitamura (1966, 1991) histologically examined human abortus with and without cleft lip/palate and identified some possible cases of cleft palate that might have passively been torn apart in utero after palatal fusion. He also showed that in human non-cleft fetuses, epithelial remnants derived from the midline epithelial seam were frequently observed to persist along the fused midline portion and that they sometimes develop into micro-cysts, known as epithelial pearls. Such epithelial pearls have always been observed in the

Abbreviations used in this paper: EGF, epidermal growth factor; MEE, medial edge epithelium; NE, nasal epithelium; OE, oral epithelium.

\footnotetext{
*Address correspondence to: Toshiya Takigawa, D.D.S., Ph.D. Department of Anatomy and Developmental Biology, Kyoto University Graduate School of Medicine, Kyoto 606-8501, Japan. Fax: +81-75-751-7529. e-mail: takigawa@cac.med.kyoto-u.ac.jp
} 
palatal edge mesenchyme in all the human cleft palate fetuses examined (Kitamura, 1966). Based on those observations, Kitamura $(1966,1991)$ claimed that the presence of the cysts in the cleft palatal edges might indicate the post-fusion rupture of the palate to take place along the midline in utero. However, the concept of the ruptured palate has scarcely been accepted by other investigators (Ferguson, 1988; Johnston, 1991; Carette and Ferguson, 1992), because the edges of cleft palate are always completely covered with epithelium in both humans and laboratory mammals, which makes the ruptured palate indistinguishable from other cleft palate cases, in which palatal shelves did not make contact with each other. Therefore, it is yet to be elucidated whether rupture of the fused palate can actually take place in utero.

It has been claimed that MEE cells never disappear unless palatal shelves make close contact with each other and a midline epithelial seam is formed (Griffith and Hay, 1992), although the actual fate of MEE cells is still controversial (Fitchett and Hay, 1989; Carette and Ferguson, 1992; Cuervo and Covarrubias, 2004; Takigawa and Shiota, 2004; Vaziri Sani et al., 2005; Dudas et al., 2006: Xu et al., 2006; Jin and Ding, 2006). Recently, we found that MEE cells can disappear from the medial edge independently of palatal shelf contact and midline seam formation under the amniotic fluid-free condition and that amniotic fluid prevents the disappearance of MEE cells unless palatal shelves make contact and the midline epithelial seam is formed (Takigawa and Shiota, 2004).

Amniotic fluid forms the major environment of mammalian fetuses grown in utero and has been suggested to play important roles in palatal fusion (Pourtois, 1968; Goss, 1976; Nanda et al., 1977; Takigawa and Shiota, 2004) as well as in development of other fetal tissues, such as the lung (Sundell et al., 1980; Yoshimura et al., 2000) and the gastro-intestinal tract (Mulvihill et al., 1985, 1986; Kelly et al., 1997). In addition, amniotic fluid has been suggested to play beneficial roles in fetal wound healing (Mast et al., 1992; Adzick and Lorenz, 1994; Özgenel et al., 2001; Levinson et al., 2001), although the mechanism is poorly understood.

The present study aimed at clarifying whether amniotic fluid influences wound repair in the palate torn apart after palatal fusion. For this purpose, we artificially separated the fused palate of mouse fetuses into halves along the midline and cultivated them in the presence or absence of mouse or human amniotic fluid in suspension culture (Shiota et al., 1990b; Takigawa and Shiota, 2004). Using this experimental model, we investigated the biological effects of amniotic fluid on the injured fetal palate. In addition, we examined the effects of exogenous EGF (epidermal growth factor) and albumin on the disappearance of MEE cells in the pre-fusion palatal shelves, as well as on wound healing in the ruptured palate, because they are major components of amniotic fluid and seemed to be responsible for the action of amniotic fluid. Our experimental study provides a new insight into the unique biological actions of amniotic fluid in the repair of the developing fetal palate when it is torn apart after palatal fusion.

\section{Results}

\section{Amniotic fluid induces epithelialization of the wound in the ruptured fetal palate}

In ICR mouse fetuses, the fusion of bilateral palatal shelves is completed by day 15.5. When the right and left palatal halves are artificially separated from each other, the naked mesenchyme is exposed on the medial surface of the wounded palatal shelves (Fig. 1 A-D). Multi-polar fibroblastic cells were observed on the surface of the wound and they were separated from each other at a distance (Fig. 1E). The nasal palatal epithelium in the ruptured palate had well differentiated into the respiratory epithelium and consisted of ciliated columnar cells and non-ciliated bulgy mucous cells (Fig. $1 \mathrm{~F}$ ). The oral palatal epithelium had differentiated into pavement-like flattened epithelium (Fig. $1 \mathrm{G}$ ).

When artificially ruptured palates were cultivated in the medium supplemented with mouse or human amniotic fluid, the palatal wound became covered with flattened epithelium (Fig. $2 \mathrm{~A}-\mathrm{F}$ ). When the palates were cultivated for 36 hours in BGJb medium only, the wound remained distinguishable from the nasal and oral epithelia (Fig. $2 \mathrm{G}, \mathrm{H}$ ), although the cells observed at the wound surface became epithelioid but not
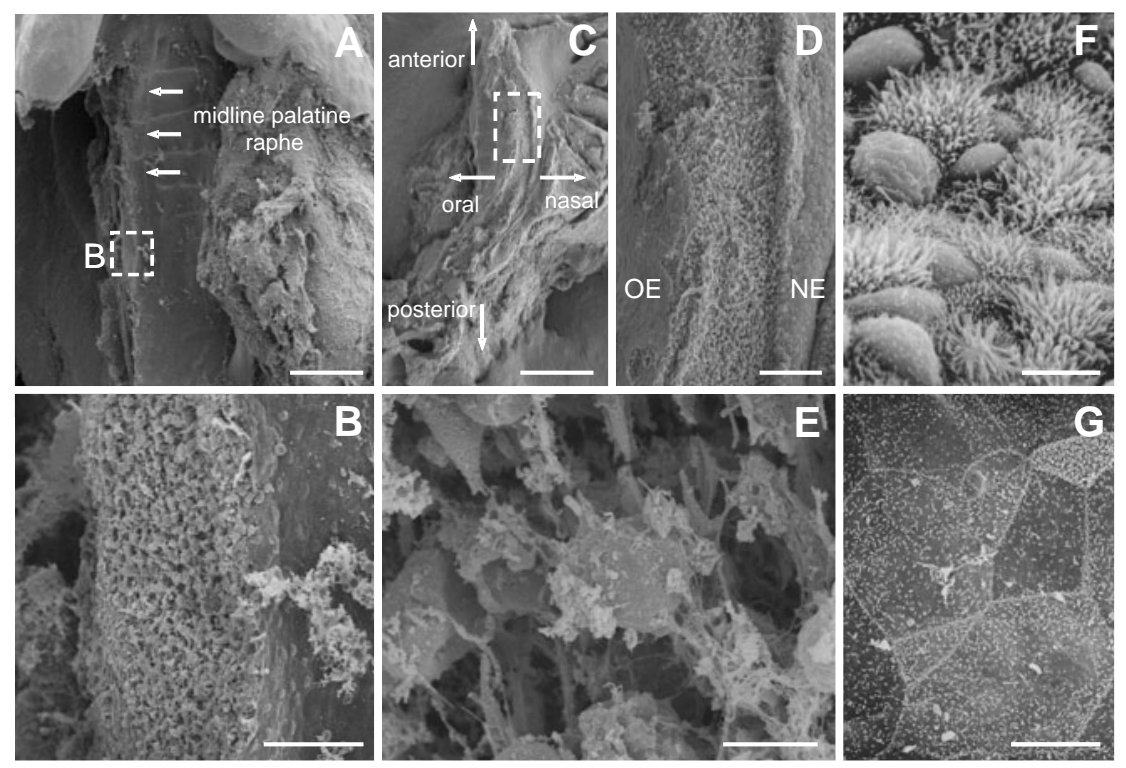

Fig. 1. SEM images of artificially ruptured palates of day 15.5 ICR mouse fetuses before culture. (A) The left side of a ruptured palate with the primary palate and nasal septum, viewed orally. Arrows indicate the midline palatal raphe where bilateral palatal shelves fused with each other. (B) Higher magnification of the boxed region in (A). The naked mesenchyme is exposed at the surface of the wounded palatal edge. (C) The right side of the palate opposite to (A), viewed medially. (D) The wounded palatal edge (the boxed region in $C$ ) is clearly distinguishable from the nasal (NE) and oral epithelia (OE). (E-G) Higher magnifications showing the cell morphology at various portions of the ruptured palate. (E) Fibroblastic cells observed at the wound surface. (F) Nasal epithelium consisting of ciliated columnar cells and non-ciliated mucous cells. (G) Flattened squamous epithelium on the oral surface of the palate. Scale bars: $(A, C) 500 \mu m ;(B, D) 100 \mu m$; (E-G) $5 \mu \mathrm{m}$. 


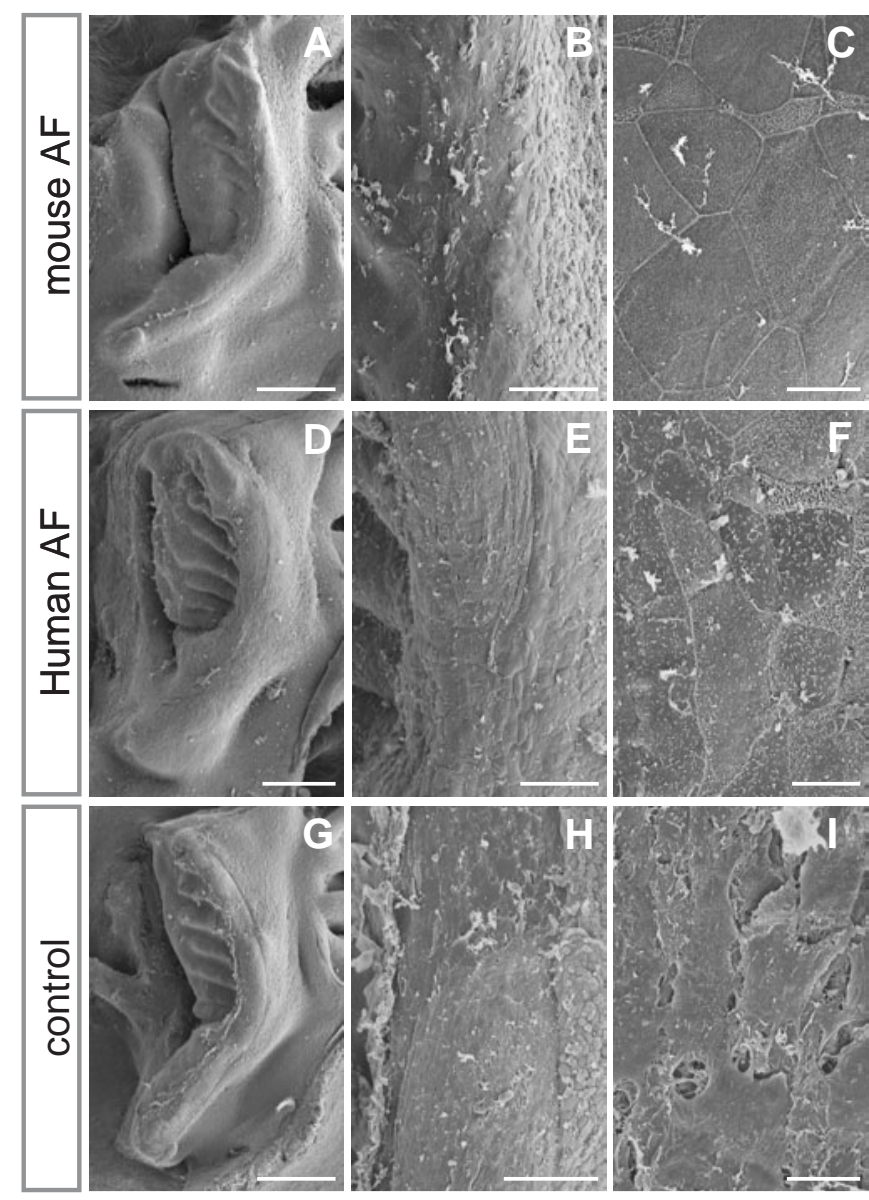

fibroblastic (Fig. 2 I). Such epithelialization of the fetal wound induced by amniotic fluid was observed at another incision surface of the mandible as well (Fig. 3 A-C).

\section{Amniotic fluid-induced wound healing process in the rup- tured fetal palate}

Before cultivating the ruptured palate with amniotic fluid, most of the cytokeratin-positive nasal and oral epithelial cells and cytokeratin-negative mesenchymal cells near the wound surface were positive for Ki-67, an indicator of proliferating cells (Fig. 4 A, B). Although epithelial remnants were sometimes observed along the fusion line between the palate and nasal septum, they were negative for $\mathrm{Ki}-67$, indicating that they did not proliferate actively (Fig. 4 B). During the wound healing in
Fig. 2. SEM images of artificially ruptured palates after 36 hours of culture. (A-C) The ruptured palate cultured for 36 hours with $80 \%$ mouse amniotic fluid of day 14.0 of gestation. (D-F) The ruptured palate cultured for 36 hours with $80 \%$ human amniotic fluid of 15 weeks of gestation. (GH) The ruptured palate cultured for 36 hours with BGJb medium only. $(\mathbf{A}, \mathbf{D}, \mathbf{G})$ Medial views of the ruptured palate after 36 hours of culture. (B,E,H) Higher magnifications of the palatal edge of (A,D and G), respectively. (C,F,I) Cell morphology observed at the palatal edge surface in (B, $E$ and H), respectively. After culture with mouse or human amniotic fluid, the wound of the ruptured palate was almost completely obliterated (A,B,D,E) and flattened epithelial cells were commonly seen at the palatal edge surface (C,F). However, when the ruptured palates were cultured with BGJb medium only, the wound remained distinguishable from the adjacent nasal and oral epithelia $(\mathbf{G}, \mathbf{H})$. Epitheloid cells were observed on the wound surface (I), which were morphologically different from the epithelial cells observed in (C and F). Scale bars: $(A, D, G) 250 \mu \mathrm{m}$; $(B, E, F) 50 \mu m ;(C, F, I) 5 \mu m$.

culture with mouse amniotic fluid, dead cells and debris were sloughed off, so that the wound surface contracted and became smooth after 12 hours of culture (Fig. $4 \mathrm{C}$ ). Although the nasal and oral epithelial cells just adjacent to the wound edge hardly showed any indication of cell proliferation, the wound edge epithelium at the nasal side appeared to gradually extend over the wound during culture (Fig. 4 C-F). Although the wound edge epithelial cells at the oral side became thickened without cell proliferation, they did not seem to extend over the wound (Fig. $4 \mathrm{E}, \mathrm{F})$.

By SEM analysis of the epithelialization process, numerous presumptive daughter cells and immature epithelial cells were observed at the wound edge epithelium at the nasal side after 12 hours in culture (Fig. 5 A, B). Subsequently, the migrating epithelial cells from the nasal epithelium took on a well-stretched, epithelioid appearance by 18 hours in culture (Fig. 5 C, D). After 36 hours of culture, the nasal epithelium-derived cells covered the entire surface of the wound in the ruptured palate (Fig. 6 A, $B)$. The epithelia covering the wound and the adjacent nasal and oral epithelia were more proliferative than those in other areas during wound healing (Fig. $6 \mathrm{C}, \mathrm{D}$ ). When the ruptured palate was cultured with human amniotic fluid, the wound was covered with the epithelium that migrated from the nasal side in a similar manner to that in culture with mouse amniotic fluid (Figs $2 \mathrm{D}-\mathrm{F}, 6 \mathrm{E}, \mathrm{F}$ ). Such wound healing was also observed in culture with $10 \%$ fetal bovine serum (Fig. $6 \mathrm{G}, \mathrm{H}$ ). On the other hand, the wound surface was never covered with the cytokeratin-positive epithelial cells in control culture (Fig. 6 I, J). Therefore, the morphologically epithelioid cells observed on the
Fig. 3. Wound healing at the incision surface of the mandible cultured with mouse amniotic fluid. (A) The incision surface of the mandible in ruptured palates of a day 15.5 mouse fetus. (B) The corresponding portion in the palate after 36 hours of culture with mouse amniotic fluid. (C) The corresponding portion in the ruptured palate after 36 hours of culture with BGJb medium only. Note that the wound of the mandible (A) was covered with flattened epithelium after culture with amniotic fluid (B), but such epithelialization was not observed in control cultures (C). Scale bars: $250 \mu \mathrm{m}$.
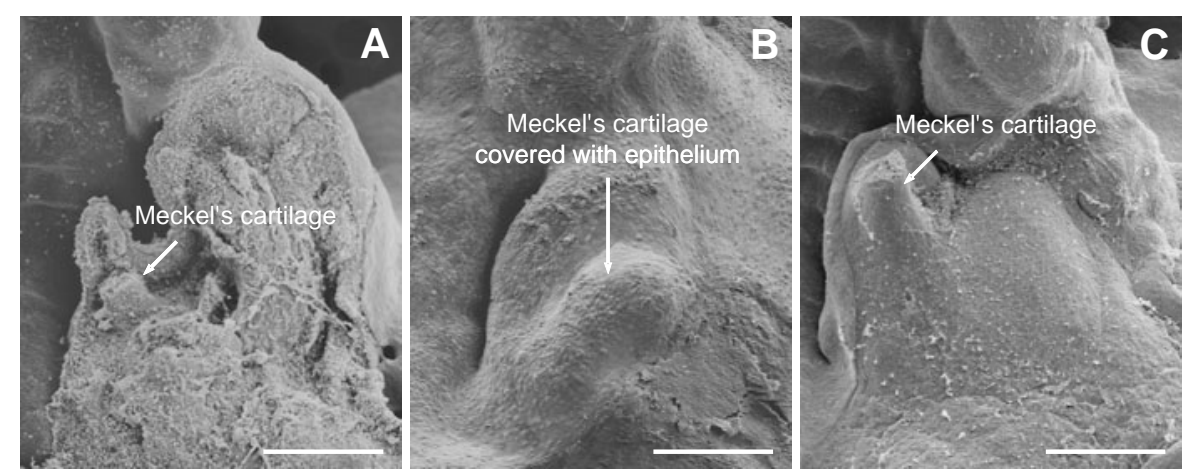
wound surface after 36 hours in the control culture were probably mesenchymal cells that expanded due to cell-cell contact with each other (Figs. 2 I, $6 \mathrm{G}, \mathrm{H}$ ).

\section{Fetal nasal epithelium is responsible for the amniotic fluid- induced rapid wound healing in the injured palate}

In order to elucidate the different responses to the action of amniotic fluid between the nasal and oral epithelial cells, we made two other types of the injured palate and cultivated these with mouse amniotic fluid. When the fused palates of day 15.5 mice were artificially separated into halves along the midline of the palate and nasal septum, the oral epithelium adjacent to the wound hardly migrated over the wound and did not show an indication of cell proliferation after 36 hours of culture with mouse amniotic fluid (Fig. 7 A-C). Similarly, when the oral epithelium was partially removed from the palate and cultured for 36 hours with mouse amniotic fluid, the epithelial defect remained exposed due to the lack of migration and cell proliferation of the adjacent oral epithelial cells (Fig. 7 D-F).

Amniotic fluid-induced rapid epithelialization in the fetal palatal wound takes place independently of the cellular signaling via EGFR and TGF $\beta$ R type I/ALK5, because the rapid epithelialization induced by amniotic fluid was not prevented with $10 \mu \mathrm{M}$ PD168393, a specific inhibitor to EGFR (Fig. 8 A, B) or $10 \mu \mathrm{M}$ SB431542, a specific inhibitor to TGF $\beta$ R type I/ALK5 (Fig. 8 C, D). The palatal mesenchyme subjacent to the wound became somewhat loose and appeared to result from reduced extracellular matrices in the mesenchyme rather than decreased cell proliferation. In addition, in the presence of amniotic fluid and PD168393, the MEE remnants in the mesenchyme disappeared (Fig. 8 A, B). In contrast, in the presence of amniotic fluid and SB431542, MEE remnants in the mesenchyme persisted and became enlarged due to cell proliferation (Fig. $8 \mathrm{C}, \mathrm{D}$ ). These findings suggest that the functions of EGFR and TGF $\beta R$ type I/ALK5 are necessary for the production of extracellular matrices in the mesenchyme during wound healing. Nevertheless, the present results indicate that amniotic fluidinduced epithelialization can take place independently of the functions of EGFR and TGF $\beta$ R type I/ALK5.

\section{Effects of amniotic fluid, fetal serum and specific inhibitors to EGFR and TGFBR type I/ALK5 on the disappearance of MEE cells and palatal fusion}

We have shown that MEE cells can disappear independently of palatal shelf contact and midline seam formation, but in the presence of amniotic fluid they cannot disappear without epithelial seam formation (Takigawa and Shiota, 2004 and Fig. 9 A-D). In the present study, we found that the effects of amniotic fluid can be replaced with $10 \%$ fetal bovine serum-added medium. The fetal bovine serum prevented MEE cell disappearance in the cultured single palatal shelf, but allowed palatal fusion when cultured in
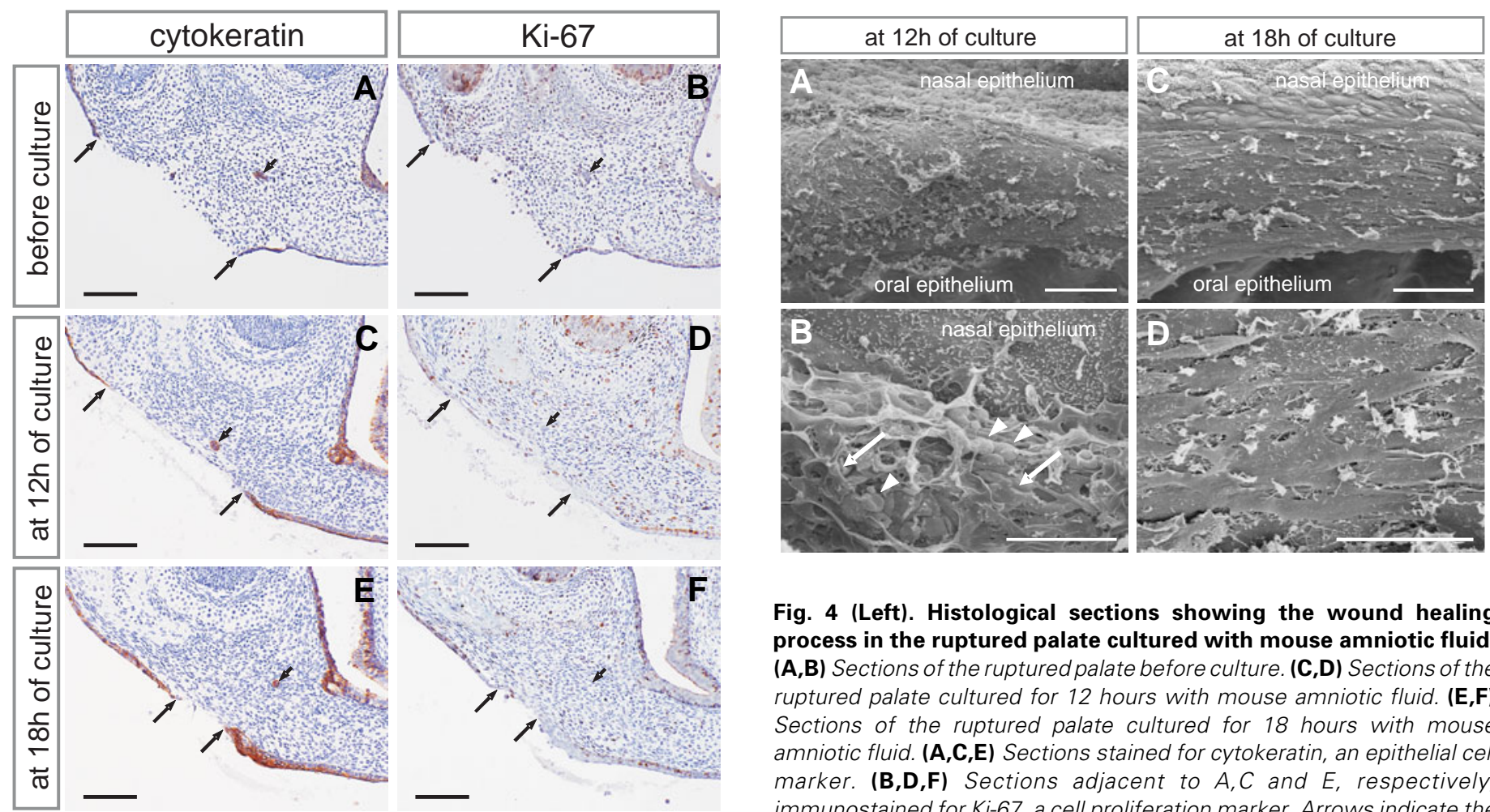

Fig. 4 (Left). Histological sections showing the wound healing process in the ruptured palate cultured with mouse amniotic fluid. $(\mathbf{A}, \mathbf{B})$ Sections of the ruptured palate before culture. (C,D) Sections of the ruptured palate cultured for 12 hours with mouse amniotic fluid. (E,F) Sections of the ruptured palate cultured for 18 hours with mouse amniotic fluid. (A,C,E) Sections stained for cytokeratin, an epithelial cell marker. (B,D,F) Sections adjacent to $A, C$ and E, respectively, immunostained for Ki-67, a cell proliferation marker. Arrows indicate the wound edge epithelium at the oral and nasal sides. Arrowheads indicate the MEE remnants observed in the ruptured palate. Scale bar: $100 \mu$ m.

Fig. 5 (Right). Cell morphology on the medial surface of ruptured palates cultured with mouse amniotic fluid. (A,B) Wounded palatal edge after 12 hours of culture. (C,D) Wounded palatal edge after 18 hours of culture. Note that the nasal mucosa expanding over the wound has become a nonciliated and flattened epithelium, similarly to the oral epithelium (B,C). Numerous daughter cells (arrowheads in B) and immature epithelial cells (arrows in $B$ ) were observed at the edge of the expanding nasal epithelium. The immature epithelial cells migrated from the nasal mucosa were well stretched and became morphologically epithelioid cells by establishing cell-cell contact with each other (D). Scale bars: (A,C) $100 \mu \mathrm{m}$; (B) $10 \mu \mathrm{m}$; (D) $30 \mu \mathrm{m}$. 


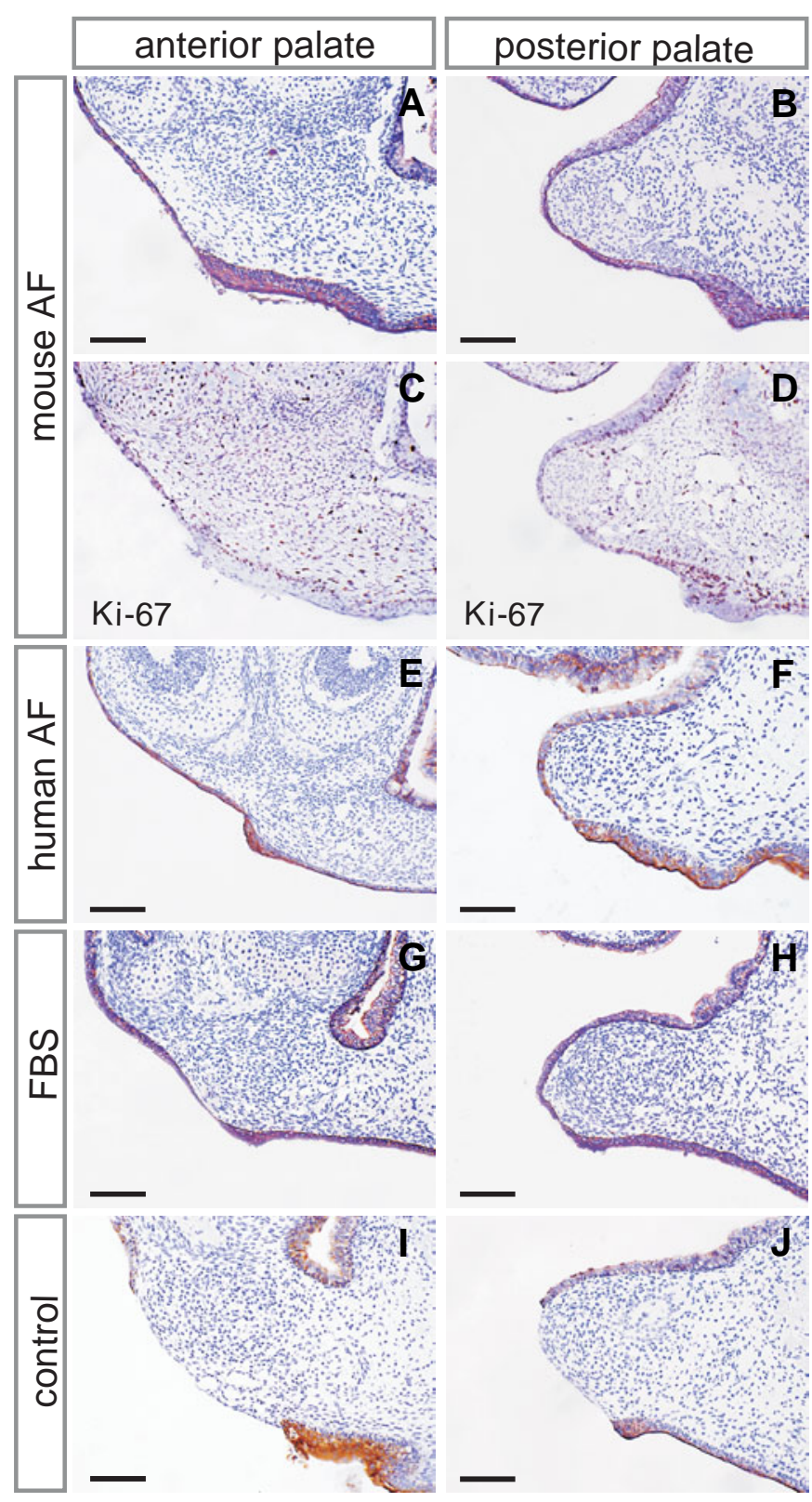

Fig. 6. Histology of the ruptured palates after 36 hours of culture with mouse and human amniotic fluid, fetal bovine serum-added medium, or with a chemically-defined medium. (A-D) The ruptured palate cultured with mouse amniotic fluid. (E,F) The ruptured palate cultured with human amniotic fluid. (G,H) The ruptured palate cultured with $10 \%$ fetal bovine serum-added medium. (I,J) The ruptured palate cultured with BGJb medium only. (A, $C, E, G$, I) Anterior portion of the ruptured palates after culture. $(B, D, F, H, J)$ The palatal edge at the posterior portion in the ruptured palates shown in (A, $C, E$ and $G$ ), respectively. (A, B, E-J) Sections immunostained for cytokeratin. (C,D) Sections adjacent to $A$ and $B$, respectively, immunostained for Ki-67. Note that the palatal wound is completely covered with flattened epithelium when cultured with mouse or human amniotic fluid $(A, B, E, F)$, or with fetal bovine serum-added medium $(G, H)$. The epithelium covering the palatal wound became proliferative after migration $(C, D)$. When cultured with BGJb medium only, the mesenchyme remained exposed at the wound surface (I,J). Scale bar: $100 \mu \mathrm{m}$.

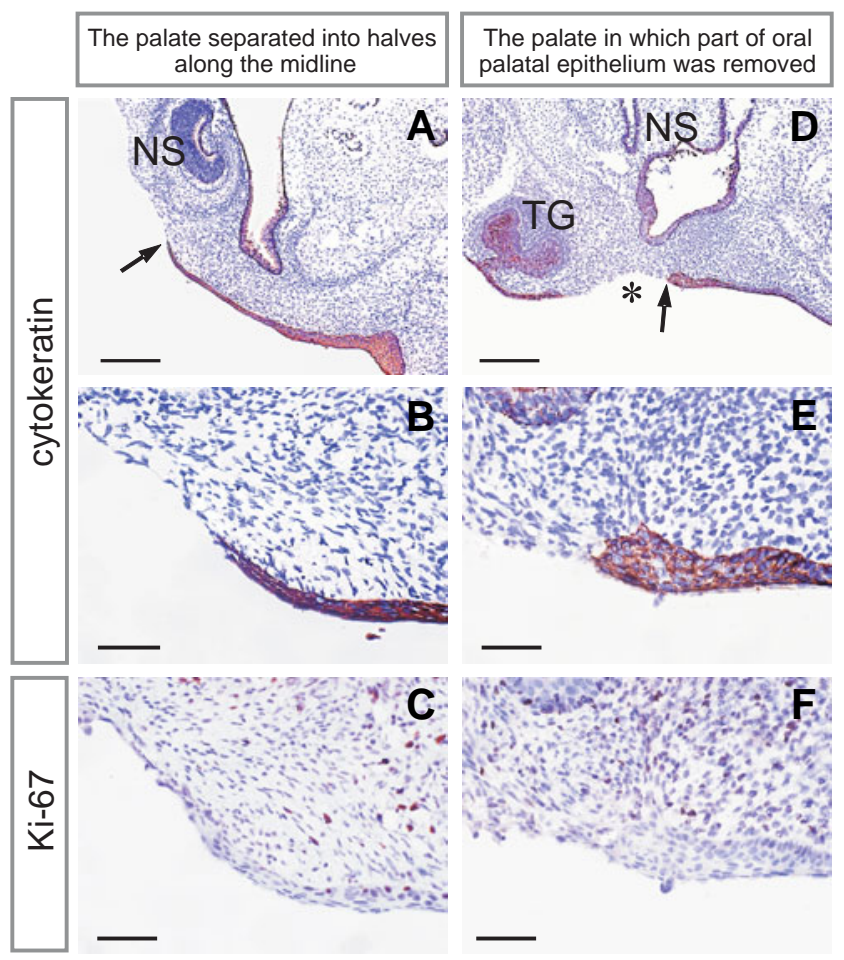

Fig. 7. Oral palatal epithelium is devoid of competence for epithelialization over the fetal wound by the action of amniotic fluid. (A-C) The anterior portion of the palate dissected into halves and cultured for 36 hours with mouse amniotic fluid. (D-F) The posterior portion of the palate in which the oral epithelium on the right side was surgically removed and cultured for 36 hours with mouse amniotic fluid. (A,B,D,E) Sections of the cultured palates were immunostained for cytokeratin. Arrows in (A) and (D) indicate the medial ends of the oral palatal epithelium. The asterisk in (D) shows the site of the epithelial defect. (B,E) Higher magnifications of the medial end of the oral palatal epithelium. (C,F) Sections adjacent to $(B, E)$, respectively, immunostained for Ki-67. Note that the oral palatal epithelium did not migrate over the epithelial defect (B,E) and showed little indication of cell proliferation (C,F). NS, nasal septum; TG, tooth germ. Scale bars: (A,D) $200 \mu \mathrm{m}$ $(B, C, E, F) 50 \mu \mathrm{m}$.

pairs (Fig. $9 \mathrm{E}, \mathrm{F}$ ). In addition, in the presence of $10 \mu \mathrm{M}$ PD168393 in culture medium, MEE cells in the cultured single palatal shelf more readily disappeared than in the control culture, but palatal fusion successfully took place when cultured in pairs (Fig. $9 \mathrm{G}, \mathrm{H}$ ). In contrast, in the presence of $10 \mu \mathrm{M} \mathrm{SB} 431542$ in culture medium, MEE cells persisted and palatal fusion never took place in single and paired palatal shelves in vitro (Fig. $9 \mathrm{I}, \mathrm{J}$ ). These findings suggest that some component(s) commonly contained in amniotic fluid and fetal bovine serum can modify the antagonism between the EGFR and TGF $\beta$ R type I/ALK5 functions and may be involved in regulating the disappearance of MEE cells and palatal fusion.

Exogenous EGF and albumin prevent MEE cell disappearance only in non-contact palatal shelves, similarly to amniotic fluid, but such actions can be canceled by treatment with a specific inhibitor to EGFR

We further examined whether exogenous EGF or albumin could mimic the effects of amniotic fluid on the pre-fusion palate, because they are biologically active among the components of 


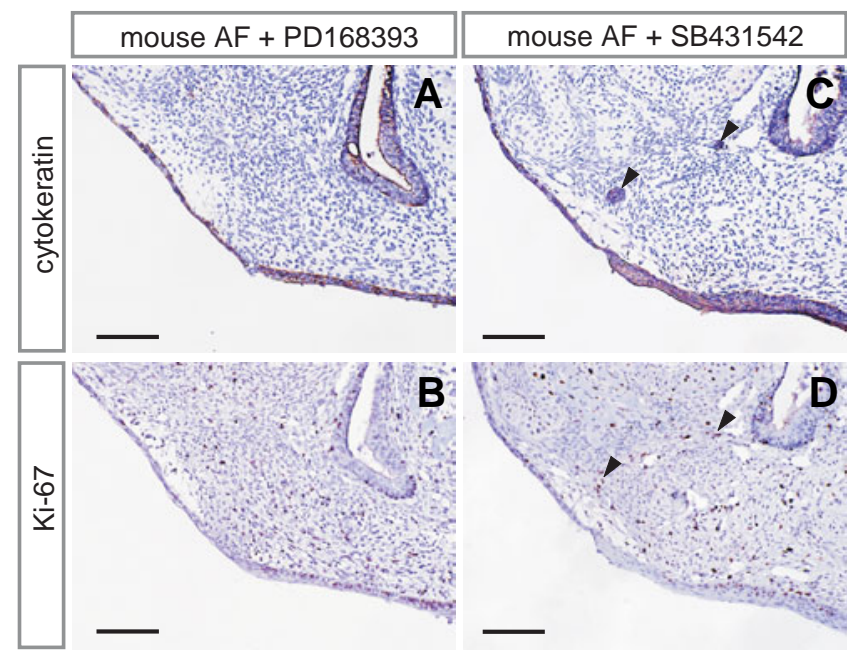

Fig. 8 (Left). Specific inhibitors of EGFR or TGFBR type I/ALK5 do not prevent the action of amniotic fluid on wound healing in ruptured palates. (A,B) Ruptured palates cultured for 36 hours with mouse amniotic fluid containing $10 \mu \mathrm{M}$ PD168393, a specific inhibitor of EGFR. (C,D) Ruptured palates cultured for 36 hours with mouse amniotic fluid containing $10 \mu \mathrm{M}$ SB431542, a specific inhibitor of TGF RR type I/ALK5. Amniotic fluid-induced epithelialization over the palatal wound was observed after 36 hours of culture even in the presence of the specific inhibitor of EGFR (A) or TGF $3 R$ type I/ALK5 (C). Although the mesenchyme subjacent to the wound became somewhat loose by treatment with both of the inhibitors, the suppression of cell proliferation was not observed in the mesenchyme (B,D). Arrowheads in $(C, D)$ indicate MEE remnants with cell proliferation in the presence of the inhibitor to TGF $\beta R$ type I/ALK5. Scale bar: $100 \mu \mathrm{m}$.

Fig. 9 (Right). Effects of amniotic fluid, fetal bovine serum and the inhibitors of EGFR and TGF $\beta R$ type I/ALK5 on MEE cells of the prefusion palatal shelves of day $\mathbf{1 4 . 0}$ mouse fetuses. (A,B) Pre-fusion palatal shelves cultured singly (A) or in pairs (B) with BGJb medium only. $(\mathbf{C}, \mathbf{D})$ Pre-fusion palatal shelves cultured singly $(C)$ or in pairs $(D)$ with human amniotic fluid. (E,F) Pre-fusion palatal shelves cultured singly (E) or in pairs (F) with 10\% fetal bovine serum-added medium. (G,H) Prefusion palatal shelves cultured singly (G) or in pairs (H) with BGJb medium containing $10 \mu \mathrm{M}$ PD168393. (I,J) Pre-fusion palatal shelves cultured singly (G) or in pairs (H) with BGJb medium containing $10 \mu \mathrm{M}$ SB431542. In control cultures, MEE cells disappeared independently of palatal shelf contact and midline seam formation (A), but amniotic fluid prevented such autonomous disappearance of MEE cells (C). Fusion of bilateral palatal shelves took place either in the presence or absence of amniotic fluid (B,D). The fetal bovine serum-added medium could mimic the effects of amniotic fluid on pre-fusion palatal shelves (E,F). When single palatal shelves were treated with $10 \mu \mathrm{M}$ PD168393, MEE cells disappeared in a large area of the medial edge (G) compared with that in control cultures, but palatal fusion took place when cultured in pairs (H). By treatment with $10 \mu \mathrm{M}$ SB431542, MEE cells persisted in the cultured single palatal shelf (I) and palatal fusion never took place in palatal shelves cultured in pairs (J). Scale bar: 100 um.

amniotic fluid. We first quantified the concentrations of albumin in mouse and human amniotic fluid and confirmed the presence of albumin in all amniotic fluid samples examined (Table 1). In the presence of $10 \mathrm{ng} / \mathrm{ml} \mathrm{EGF}$ or $5 \mathrm{mg} / \mathrm{ml}$ bovine serum albumin in culture medium, MEE cells in the single palatal shelf persisted after 36 hours of culture (Fig. $10 \mathrm{~A}, \mathrm{E}$ ), although palatal fusion was not prevented in these cultures (Fig. B, F), similarly to the culture with amniotic fluid. However, by adding $10 \mu$ M PD168393 with 10 $\mathrm{ng} / \mathrm{ml} \mathrm{EGF}$ or $5 \mathrm{mg} / \mathrm{ml}$ bovine serum albumin to the culture medium, MEE cells disappeared in the cultured single palatal shelf (Fig. $10 \mathrm{C}, \mathrm{G}$ ). When human serum albumin was used, the results were the same as those in culture with bovine serum

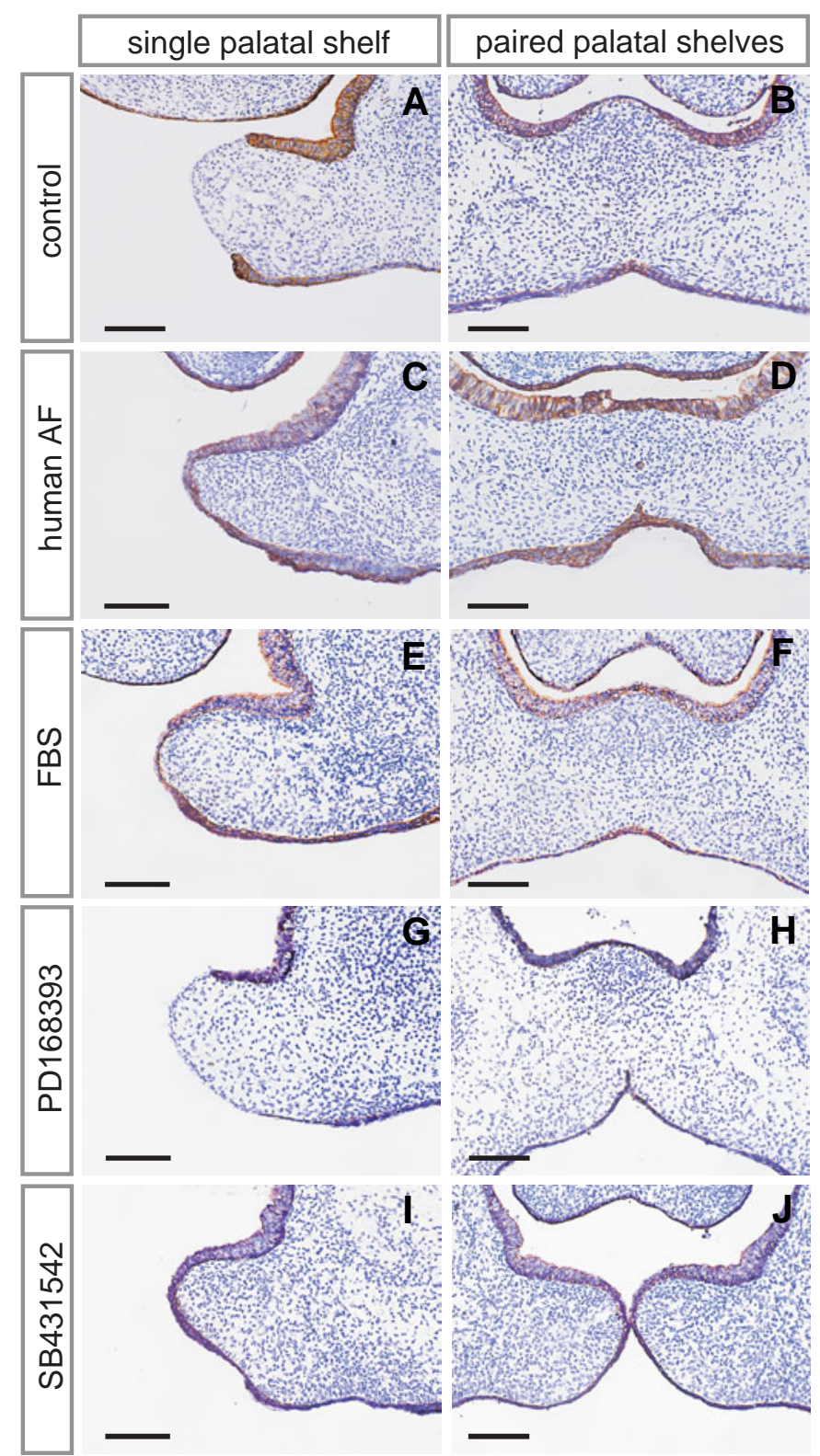

albumin (data not shown). These results indicate that not only EGF, but also albumin can prevent the disappearance of MEE cells by cellular signaling via EGFR unless palatal shelves make close contact with each other and form a midline epithelial seam.

\section{Amniotic fluid can induce the replacement of palatal edge epithelium from MEE cells to nasal epithelium-derived cells in the non-contact palatal shelves when EGFR functions are suppressed \\ When the pre-fusion palatal shelves of E 14.0 ICR mice were} cultured singly in the medium supplemented with mouse amniotic fluid or $10 \%$ fetal bovine serum together with $10 \mu \mathrm{M}$ 
PD168393, the MEE cells disappeared from the palatal edge after 24-36 hours in culture (Fig. 11 A, C). However, the epithelial defects resulting from the disappearance of MEE cells became re-epithelialized by nasal epithelium-derived cells by incubation for another 36 hours with the same medium (Fig. $11 \mathrm{~B}, \mathrm{D})$. Thus, it is likely that the inhibitory action of amniotic fluid and fetal serum on the disappearance of MEE cells in noncontact palatal shelves, as shown in Fig. $9 \mathrm{C}$ and $\mathrm{E}$, is dependent on the cellular signaling via EGFR. However, amniotic fluid and fetal serum can induce rapid epithelialization indepen- dently of the EGFR function, in a similar manner as that in the ruptured palate, as shown in Fig. $8 \mathrm{~A}$ and $\mathrm{B}$.

\section{Spontaneous excencephaly and myeloshisis cases in fetal mice suggest the presence of regional heterogeneity in the epithelial response to the action of amniotic fluid}

We found some cases of spontaneous excencephaly $(n=3)$ and lumbosacral myeloshisis $(n=1)$ in day 14.0 fetuses of ICR mice (Fig. 12A-H). Generally, excencephaly and lumbosacral myeloshisis result from a failure of closure of the anterior and posterior
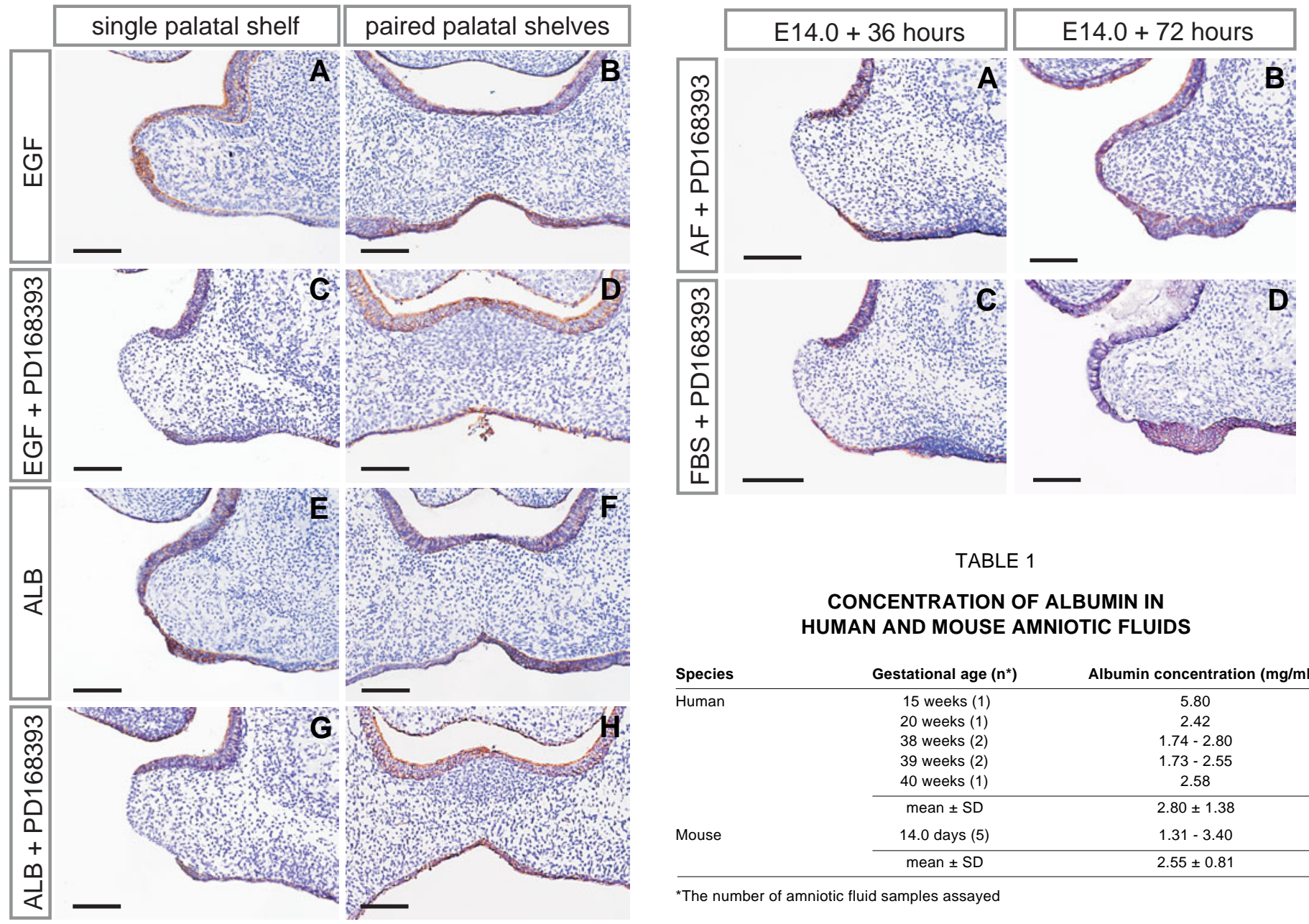

TABLE 1

\section{CONCENTRATION OF ALBUMIN IN HUMAN AND MOUSE AMNIOTIC FLUIDS}

\begin{tabular}{lcc} 
Species & Gestational age $\left(\mathbf{n}^{\star}\right)$ & Albumin concentration $(\mathbf{m g} / \mathbf{m l})$ \\
\hline Human & 15 weeks $(1)$ & 5.80 \\
& 20 weeks (1) & 2.42 \\
& 38 weeks (2) & $1.74-2.80$ \\
& 39 weeks (2) & $1.73-2.55$ \\
& 40 weeks (1) & 2.58 \\
\hline Mouse & mean \pm SD & $2.80 \pm 1.38$ \\
& 14.0 days (5) & $1.31-3.40$ \\
\hline & mean \pm SD & $2.55 \pm 0.81$
\end{tabular}

*The number of amniotic fluid samples assayed

Fig. 10 (Left). Exogenous EGF and albumin mimic the effects of amniotic fluid on MEE cells and the inhibitor to EGFR prevents the effects of EGF and albumin. (A,B) Pre-fusion palatal shelves cultured singly (A) or in pairs (B) with BGJb medium containing of $10 \mathrm{ng} / \mathrm{m} / \mathrm{EGF}$. (C,D) Pre-fusion palatal shelves cultured singly (C) or in pairs (D) with BGJb medium containing $10 \mathrm{ng} / \mathrm{ml}$ EGF and $10 \mu M$ PD168393. (E,F) Pre-fusion palatal shelves cultured singly (E) or in pairs (F) with BGJb medium containing $5 \mathrm{mg} / \mathrm{ml}$ bovine serum albumin. (G,H) Pre-fusion palatal shelves cultured singly (G) or in pairs (H) with BGJb medium containing $5 \mathrm{mg} / \mathrm{ml}$ bovine serum albumin and $10 \mu M$ PD168393. Note that exogenous EGF and albumin prevented MEE cell disappearance in the single palatal shelf, but palatal fusion occurred successfully when bilateral palatal shelves were cultured in pairs, similarly to that in cultures with amniotic fluid (A,B,E,F). However, treatment with $10 \mu \mathrm{M} P D 168393$ completely canceled the actions of EGF and albumin on MEE cell disappearance in the cultured single palatal shelf $(C, G)$.

Fig. 11 (Right). Replacement of the palatal edge epithelium from native MEE cells to nasal epithelium-derived cells when EGFR functions were inhibited by PD168393. (A,B) Pre-fusion palatal shelves cultured singly for 36 hours $(A)$ and 72 hours $(B)$ with mouse amniotic fluid containing $10 \mu M$ PD168393. (C,D) Pre-fusion palatal shelves cultured singly for 36 hours (C) and 72 hours (D) with fetal bovine serum-added medium containing $10 \mu \mathrm{M}$ PD168393. When the single palatal shelf was cultured with amniotic fluid or fetal bovine serum-added medium containing $10 \mu \mathrm{M}$ PD168393, the MEE cells disappeared after 36 hours of culture (A,C). However, the palatal edges became completely re-epithelialized by nasal epithelium-derived cells during another 36 hours of culture (B,D). Scale bar: $100 \mu \mathrm{m}$. 

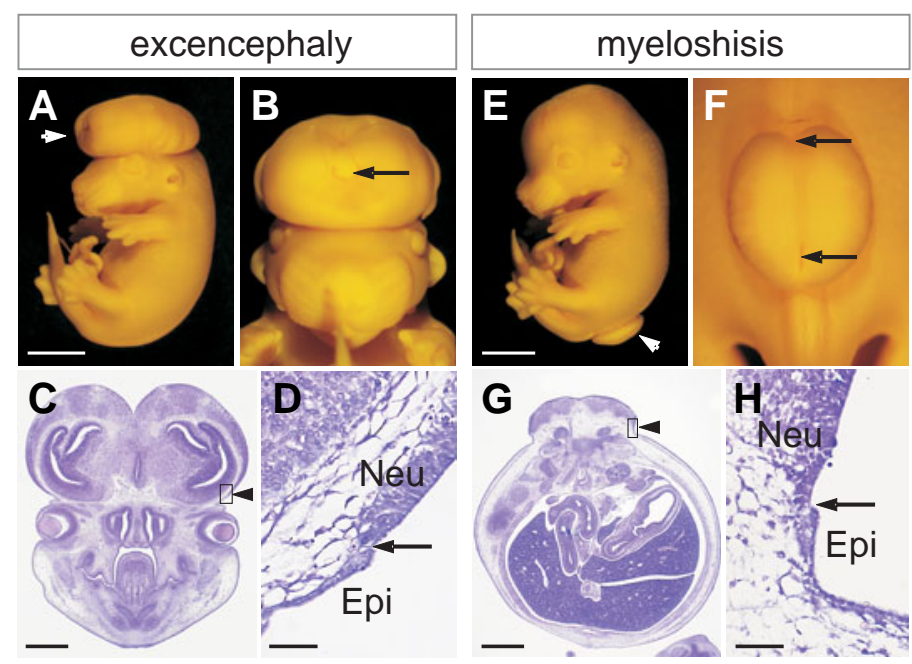

Fig. 12. The naked central nervous tissues in mouse fetuses associated with spontaneous excencephaly or myeloschisis. (A-D) $A$ day 14.0 mouse fetus with excencephaly. (A) Lateral view of the fetus and (B) frontal view of the head. Arrowhead in (A) indicates the excencephaly and arrow in $(B)$ indicates the opening of the third ventricle to the surface. (C) A frontal section of the excencephalic head. (D) A higher magnification of the portion indicated in the box in (C). Arrow in (D) indicates the boundary between the epidermis (Epi) and the naked brain tissues (Neu). (E-F) A day 14.0 mouse fetus with lumbosacral myeloshisis. (E) Lateral view of the fetus and (F) dorsal view of the myeloshisis. Arrowhead in (E) indicates the myeloshisis and arrows in (F) indicate the opening of central canal to the surface. (G) A transverse section to the body axis through the myeloshisis. (H) A higher magnification of the portion indicated in the box in (G). Arrow in $G$ indicates the boundary between epidermis (Epi) and the naked spinal tissues (Neu). Scale bars: $(A, E) 2 \mathrm{~mm} ;(C, G) 500 \mu \mathrm{m} ;(D, H)$ $50 \mu \mathrm{m}$.

neuropores, respectively. By histological analysis of such mouse fetuses with neural tube defects, the neural tissues were exposed directly to the amniotic cavity with no sign of covering by the adjacent dura mater or epithelial tissue (Fig. $12 \mathrm{C}, \mathrm{D}, \mathrm{G}, \mathrm{H}$ ). In human fetuses, it has been reported that myeloshisis is often converted into myelomeningocele after the nude spinal cord is covered with scar tissue and flattened epithelium (Cameron, 1956). However, in our cases in mice, the naked neural tissues remained healthy without epithelial covering until day 14.0. These observations suggest that the epithelial response to the action of amniotic fluid may be regionally heterogeneous, as observed in the nasal and oral palatal epithelia.

\section{Discussion}

Kitamura $(1966,1991)$ examined the human fetal specimens with cleft palate and suggested the possibility that cleft palate can be produced by post-fusion rupture of the palate. Since flattened epithelia were usually observed at the border of the cleft palatal shelves and at the base of the nasal septum, he postulated that if the rupture of the once fused palate takes place in utero, oral epithelial cells would cover the torn portion by migrating over the epithelial defect. However, his hypothesis was not supported by experimental studies.

In the present study, we revealed the ability of amniotic fluid to promote the healing of the wound in the ruptured fetal palate, using an in vitro experimental model simulating the intrauterine environment. Our results suggested that if post-fusion rupture of the fetal palate takes place in utero, the wound may be promptly epithelialized by the action of amniotic fluid. While amniotic fluid stimulated proliferation of the wound edge nasal epithelium and its migration over the wound, the palatal epithelium orally adjacent to the wound hardly participated in the epithelialization, which is inconsistent with the hypothesis proposed by Kitamura (1991). In addition, our SEM analysis showed that the nasal epithelium-derived cells over the wound lost the morphological characteristics of the well-differentiated nasal epithelium and became a flattened epithelium resembling the oral epithelium. This observation suggests that the fetal nasal epithelium can produce flattened epithelium even after it has differentiated into the respiratory epithelium under accidental situations, such as wound repair. It is also interesting to note that unlike the oral palatal epithelium, the fetal buccal epithelium consisting of nonstratified, cuboidal epithelial cells also underwent cell proliferation and migration in response to the stimulation of amniotic fluid, similarly to the fetal nasal epithelium. In addition, our observation of the naked neural tissues in the fetal mice with spontaneous excencephaly and myeloschisis supported such regional heterogeneity in the epithelial response to the action of amniotic fluid and suggested the requirement of appropriate epithelial-mesenchymal interactions for fetal wound healing.

Like our results in the present study, the process of wound healing in the fetus has been shown to be different from that in the adult by previous investigators. It has been shown that rapid healing, the lack of an inflammatory response, the absence of neovascularization and the absence of scar formation are unique to fetal wound healing (Sancho et al., 1997). Both the properties of the immature fetal tissues and the unique fetal environment, including amniotic fluid, have been suggested to be responsible for the fetal wound healing (Mast et al., 1992; Adzick and Lorentz, 1994; Sancho et al., 1997), but the mechanisms underlying the healing process of the fetal wound are poorly understood. Our present study clearly showed that wound healing in the injured fetal palate is facilitated in culture with amniotic fluid but not in culture without it. The roles of some factors in amniotic fluid have been examined, such as hyaluronic acid, fibronectin, tenascin and several growth factors (Whitby and Ferguson, 1991; Sancho et al., 1997; Mackool et al., 1998; Levinson et al., 2001; Tammi et al., 2005), but no single component has been shown to be responsible for the fetal wound healing. Our in vitro fetal wound model used in this study could cause minimal inflammation owing to the lack of fetal circulation; nevertheless, it showed rapid healing without scar formation due to the action of the amniotic fluid. Such a promotive effect of the amniotic fluid on wound healing could be replicated only with fetal bovine serum-added medium, suggesting that the factor(s) responsible for the reepithelialization may be some component(s) commonly contained in amniotic fluid and fetal serum, but are not amniotic fluidspecific.

Human amniotic fluid contains high concentrations of EGF (10$65 \mathrm{pg} / \mathrm{ml}$ ), which is probably secreted by the amniotic membrane and fetal kidney and the fetus continuously swallows the EGF-rich amniotic fluid during gestation (Kelly et al., 1997). EGF is regarded as a major component responsible for the effects of the 
swallowed amniotic fluid on the development of various organs, such as the lung and gastro-intestinal tract (Sundell et al., 1980; Goodlad et al., 1987; Kelly et al., 1997) and EGFR has been shown to be expressed in those fetal tissues (Mulvihill etal., 1986; Jansson and Skarland, 1990; Varner et al., 1996; Kelly et al., 1997; Yoshimura, et al., 2000). EGFR is normally expressed in the disappearing MEE at the time of palatal fusion and is assumed to play roles in palatogenesis (Shiota et al., 1990a), but its significance in normal and abnormal palate development remains to be elucidated. Previous studies showed that palatal fusion is dependent on the action of TGF $\beta 3$ (Proetzel etal., 1995; Kaartinen et al., 1995; Taya et al., 1999) and TGF $\beta 3$-induced activation of Smad2 is a prerequisite for MEE disappearance during palatal fusion (Cui et al., 2003; Greene et al., 2003; Dudas et al., 2004). Recently, Yamamoto et al. (2003) showed that exogenous EGF induces the over-stimulation of mitogen-activated protein kinases ERK1/ERK2 via the EGFR and results in the persistence of the midline epithelial seam in the fusing palate in culture, suggesting that the excess EGF overrides the TGF $\beta 3$-dependent activation of Smad2 in MEE cells.

In the present study, we showed that the exogenous EGF at a concentration of $10 \mathrm{ng} / \mathrm{ml}$ in culture medium can prevent the disappearance of MEE cells in non-contact palatal shelves, but allowed palatal fusion successfully in paired palatal shelves in culture, similarly to the action of amniotic fluid. However, the physiological amount of EGF (e.g., $50 \mathrm{pg} / \mathrm{ml}$ ) in amniotic fluid, as was quantified by Kelly et al. (1997), was not sufficient to prevent the disappearance of MEE cells in pre-fusion palatal shelves in culture (data not shown). In this regard, we postulated that besides EGF, some other component(s) of amniotic fluid may have an EGF-like action. Although components of amniotic fluid are not fully defined, albumin is known to be abundant in amniotic fluid as well as in fetal serum throughout pregnancy (Gustine and Zimmerman, 1972; Bala et al., 1987; this study). In addition, albumin has been shown to activate ERK1/ERK2 via EGFR in renal epithelial cells (Reich et al., 2005). Therefore, we examined the effects of albumin on the fetal palate and found that albumin alone could prevent the disappearance of MEE cells in the cultured single palatal shelf at close to its physiological concentrations in human and mouse amniotic fluids. Furthermore, the inhibition of EGFR functions by PD168393 in culture clearly demonstrates that the preventive effects of EGF, albumin, fetal serum and amniotic fluid on the disappearance of MEE cells are dependent on the intracellular signaling via EGFR in MEE cells. Taking these results together, albumin alone or its synergy with EGF is most likely to be responsible for the preventive effect of amniotic fluid on the disappearance of MEE cells in non-contact cleft palate ("primary clefting of the palate"). On the other hand, when the palate becomes cleft by rupture during or just after the fusion in utero ("secondary clefting of the palate"), which was suggested by Kitamura (1966; 1991), amniotic fluid seems to not only sustain the MEE remnants to persist in the palatal mesenchyme, but also induces rapid epithelialization of the injured palatal edges.

As for the cleft palate occasionally seen in Egfr-deficient mice (Sibilia and Wanger, 1995; Threadgill et al., 1995), the cleft formation is assumed to result from a failure of the bilateral palatal shelves to make contact by severe growth retardation of the mandible, or owing to rupture of the palate caused by the failure of the midline epithelial seam to disrupt (Miettinen et al., 1999). In the absence of EGFR functions, our study showed that palatal edge epithelium can be replaced by nasal epithelium-derived cells by the action of amniotic fluid, unless the palatal shelves form a midline epithelial seam. Therefore, it may be worth testing whether such epithelial replacement takes place in the cleft palate in Egfr-deficient mice. Furthermore, Dudas et al. (2006) and Xu et al. (2006) recently showed that in $A / k 5^{f l o x / f l o x} / K 14-C r e a n d ~ T g f b r 2^{f l o x}$ flox/K14-Cre mutant mice, the cleft phenotype restricted to the posterior part of the soft palate can result partly from rupture of the submucous cleft palate because the palate is pulled apart as the head grows; nevertheless, the cleft palatal edges are always completely covered with intact epithelium. These observations are consistent with our results that EGFR and TGF $\beta$ R type I/ALK5 functions are not essential for rapid epithelialization of the palatal wound induced by the action of amniotic fluid.

In summary, our present study has revealed the hitherto unknown unique actions of amniotic fluid for wound healing in the injured fetal mouse palate. Amniotic fluid not only gives the fetus a physical space for growth and movement in utero, but also seems to exert some important biological actions on developing fetal tissues, including normal and abnormal palates.

\section{Materials and Methods}

\section{Animals}

Mature female ICR mice (Japan SLC Inc., Shizuoka, Japan) were mated overnight with a male and noon on the day on which a vaginal plug was found was designated as day 0.5 of development. Pregnant females were sacrificed by cervical dislocation on day 14.0 or 15.5 of gestation and the fetuses were removed from the uterus for cultivation. All animal experiments in this study were performed in accordance with the principles of laboratory animal care at Kyoto University Graduate School of Medicine and were approved by the animal research committee.

\section{Amniotic fluids}

The timed fetuses with intact amniotic sacs were aseptically removed from the uterus. The amniotic sac was punctured with the sharpened tip of tweezers and the amniotic fluid was carefully collected from each sac with a syringe, avoiding contamination with blood. Human amniotic fluids from 15 weeks of gestation to full term were collected at therapeutic abortion or cesarian section with informed consent obtained from each patient in advance. The concentration of albumin in the fluid samples collected was estimated using the bromeresol green dye-binding method (Gentry and Lumsden, 1978). The amniotic fluids were immediately cleared by centrifugation at $10,000 \times g$ for 20 minutes at $4^{\circ} \mathrm{C}$ and stored at $-20^{\circ} \mathrm{C}$ until use.

\section{Palate organ cultures}

The maxillary portion was removed from each fetus by making two horizontal incisions through the head at the levels of the eye and oral angle. The right palatal portion of the fused palate of the day 15.5 fetus was further ripped with tweezers and was used as the ruptured palate. An incision was made just right to the midline of the palate, so that if the MEE remnants remained along the fusion line, the fate of the cells could be examined. In addition, two other types of incision were made. One was made along the midline to separate the palate and nasal septum into the halves and another was made to remove only the unilateral oral epithelium of the palate. The explants were cultured according to the suspension culture method (Shiota et al., 1990b;Takigawa and Shiota, 2004). Briefly, three to five explants were put into a $50 \mathrm{ml}$ size of culture bottle with $5 \mathrm{ml}$ of BGJb medium (Invitrogen), or amniotic fluid of mice or humans, which was diluted with BGJb medium to a concentration of $80 \%(\mathrm{v} / \mathrm{v})$.

In order to compare the effects of EGF, albumin, or fetal serum on the 
fetal palate with those of amniotic fluid, pre-fusion palates of day 14.0 fetuses were also used as single or paired palatal shelf explants.

To examine whether the effects of amniotic fluid can be replaced with exogenous EGF or albumin, mouse submandibular glands-derived EGF (\#01-101, Upstate Biotechnology Inc.) or albumin, fraction $V$, which is highly purified from bovine serum (A-2058, SIGMA) or human serum (A8763 , SIGMA), was added to BGJb medium at a concentration of $10 \mathrm{ng} / \mathrm{ml}$, $5 \mathrm{mg} / \mathrm{ml}$, respectively. When the effects of fetal serum on the fetal palates were examined, fetal bovine serum (SIGMA) was added to BGJb medium at the concentration of $10 \%(\mathrm{v} / \mathrm{v})$.

In addition, to examine whether the action of amniotic fluid on the fetal palate is dependent on the signaling via EGFR (EGF receptor) or TGF $\beta R$ (TGF $\beta$ receptor), PD168393 (a specific inhibitor to EGFR) (Merck Ltd., Tokyo, Japan) or SB431542 (a specific inhibitor to TGF $\beta$ R type I/ALK5) (Tocris Cookson Ltd., Bristol, UK) was added to the BGJb medium at a concentration of $10 \mu \mathrm{M}$. As controls of those chemical inhibitors, $0.05 \%$ DMSO was used and the absence of an effect of the solvent per se on the fetal palatal tissues was preliminarily confirmed.

The culture bottles were flushed for about 2-3 min with a gas-mixture of $95 \% \mathrm{O}_{2} / 5 \% \mathrm{CO}_{2}$ and sealed with a rubber stopper and a metal cramp. They were incubated at $37^{\circ} \mathrm{C}$ on a roller device at $25-30 \mathrm{rpm}$ for 36 hours, or sometimes further incubated for 36 hours after the culture medium and gas were changed. At least five palates were cultivated in control cultures with BGJb medium and each experimental group.

\section{Scanning electron microscopy (SEM)}

For SEM observation, fetal palates before and after culture were fixed with PLP-GA (periodate-lysine-paraformaldehyde-fixative solution containing $2.5 \%$ glutaraldehyde) at $4^{\circ} \mathrm{C}$ for $3-5$ days. After post-fixation with $1 \%$ $\mathrm{OsO}_{4}$ for 2 hours, they were dehydrated, dried and coated with a thin layer of gold. The specimens were examined with a Hitachi S-4700 scanning electron microscope (Hitachi, Tokyo, Japan).

\section{Histological analysis}

The palatal shelves after culture were fixed in PLP for $6-12$ hours at $4^{\circ} \mathrm{C}$, embedded in paraffin and serially sectioned ( $5 \mu \mathrm{m}$ thick). Sections taken every $50 \mu \mathrm{m}$ were stained with hematoxylin and eosin for routine histology. Other sections were examined by immunostaining for cytokeratin with a mouse monoclonal antibody, clone AE1+AE3 (DAKO JAPAN, Kyoto, Japan) and for a nuclear antigen of proliferating cells, Ki-67, with a rabbit polyclonal antibody (YLEM, Rome, Italy). For retrieval of the antigen, sections were digested with $20 \mu \mathrm{g} / \mathrm{ml}$ proteinase $\mathrm{K}$ (Wako pure chemicals Inc., Kyoto, Japan) dissolved in PBS (10 mM phosphate buffer, pH 7.4) at $37^{\circ} \mathrm{C}$ for $12 \mathrm{~min}$ for cytokeratin-immunostaining, or boiled in $0.01 \mathrm{M}$ citric acid buffer, $\mathrm{pH} 6.0$ at $95^{\circ} \mathrm{C}$ for 30 min for Ki-67-immnunostaining and immersed in methanol containing $0.03 \%$ hydrogen peroxide for 20 min to quench the endogenous peroxidase activity. Then, the sections were incubated with the primary antibody overnight at $4^{\circ} \mathrm{C}$ and rinsed in PBS, followed by incubation with a horseradish peroxidase-conjugated antimouse IgG antibody or an anti-rabbit antibody for 1 hour at room temperature. Immunoproducts were visualized with a peroxidase-substrate solution that consisted of $0.02 \% 3-3$ '-diaminobenzidine and $0.005 \%$ hydrogen peroxide in $50 \mathrm{mM}$ Tris- $\mathrm{HCl}$ buffer ( $\mathrm{pH} 7.6)$. After the visualization, they were counterstained with hematoxylin. No immunostaining was confirmed in the negative control samples with preimmune mouse lgG or rabbit lgG (DAKO JAPAN, Kyoto, Japan) instead of the primary antibodies. In our experience, the indirect immunostaining method with a mouse monoclonal antibody against cytokeratin can be applicable on the PFA (paraformaldehyde) or PLP-fixed, paraffin-embedded sections of mouse fetal tissues (Takigawa and Shiota, 2004 and this study). The reproducibility of the results in each experiment was confirmed by histologically analyzing five or more cultured palates.

\section{Acknowledgements}

We thank Mr. Makio Fujioka and Ms. Keiko Furuta for assistance in scanning electron microscopy. This study was supported by Grants-in-aid for Scientific Research from the Japanese Ministry of Education, Culture, Sports, Science and Technology.

\section{References}

ADZICK NS, LORENZ HP. (1994). Cells, matrix, growth factors, and the surgeon. The biology of scarless fetal wound repair. Ann Surg 220:10-18.

BALA S, SETH S, SETH PK. (1987). Albumin concentration in human amniotic fluid from normal pregnancies. Acta Paediatr. Hung. 28:187-192.

CAMERON AH. 1956. The spinal cord lesion in spina bifida cystica. Lancet 271:171-174.

CARETTE MJ, FERGUSON MW. (1992). The fate of medial edge epithelial cells during palatal fusion in vitro: an analysis by Dil labelling and confocal microscopy. Development 114:379-388.

CUERVO R, COVARRUBIAS L. (2004). Death is the major fate of medial edge epithelial cells and the cause of basal lamina degradation during palatogenesis. Development 131:15-24.

CUI XM, CHAI Y, CHEN J, YAMAMOTO T, ITO Y, BRINGAS P, SHULER CF. (2003). TGF-beta3-dependent SMAD2 phosphorylation and inhibition of MEE proliferation during palatal fusion. Dev Dyn 227:387-394.

DUDAS M, NAGY A, LAPING NJ, MOUSTAKAS A, KAARTINEN V. (2004). Tgfbeta3-induced palatal fusion is mediated by Alk-5/Smad pathway. Dev Biol 266:96-108.

DUDAS M, KIM J, LI WY, NAGY A, LARSSON J, KARLSSON S, CHAI Y, KAARTINEN V. (2006). Epithelial and ectomesenchymal role of the type I TGFbeta receptor ALK5 during facial morphogenesis and palatal fusion. Dev Biol. 296: 298-314.

FERGUSON MW. (1988). Palate development. Development 103 Suppl:41-60.

FITCHETT JE, HAY ED. (1989). Medial edge epithelium transforms to mesenchyme after embryonic palatal shelves fuse. Dev Biol131:455-474.

GENTRY PA, LUMSDEN JH. (1978). Determination of serum albumin in domestic animals using the immediate bromeresol green reaction. Vet Clin Patho/7:1215.

GOODLAD RA, WILSON TJ, LENTON W, GREGORY H, MCCULLAGH KG, WRIGHT NA. (1987). Proliferative effects of urogastrone-EGF on the intestinal epithelium. Gut28(Suppl): 37-43.

GOSS AN. (1976). Amniotic fluid and rat palatal fusion in vitro. Arch Oral Biol $21: 631-632$

GREENE RM, NUGENT P, MUKHOPADHYAY P, WARNER DR, PISANO MM. (2003). Intracellular dynamics of Smad-mediated TGFbeta signaling. J Cell Physio/197:261-271.

GRIFFITH CM, HAY ED. (1992). Epithelial-mesenchymal transformation during palatal fusion: carboxyfluorescein traces cells at light and electron microscopic levels. Development 116:1087-1099.

GUSTINE DL, ZIMMERMAN EF. (1972). Amniotic fluid proteins: Evidence for the presence of fetal plasma glycoproteins in mouse amniotic fluid. Am. J. Obstet. Gynecol. 114: 553-560.

JANSSON T, SKARLAND H. (1990). Maternally administered epidermal growth factor stimulates fetal growth in the rat. Acta Physio/ Scand 138:245-246.

JIN JZ, DING J. (2006). Analysis of cell migration, transdifferentiation and apoptosis during mouse secondary palate fusion. Development 133:3341-3347.

JOHNSTON MC. (1991). Commentary. Cleft Palate Craniofac J28:210-211.

JOHNSTON MC, BRONSKY PT. (1995). Prenatal craniofacial development: new insights on normal and abnormal mechanisms. Crit Rev Oral Biol Med6:368422.

KAARTINEN V, VONCKEN JW, SHULER C, WARBURTON D, BU D, HEISTERKAMP N, GROFFEN J. (1995). Abnormal lung development and cleft palate in mice lacking TGF-beta 3 indicates defects of epithelial-mesenchymal interaction. Nat Genet 11:415-421.

KELLY EJ, NEWELL SJ, BROWNLEE KG, FARMERY SM, CULLINANE C, REID WA, JACKSON P, GRAY SF, PRIMROSE JN, LAGOPOULOS M. (1997). Role of epidermal growth factor and transforming growth factor alpha in the developing stomach. Arch Dis Child Fetal Neonatal Ed76:F158-162. 
KITAMURA H. (1966). Epithelial remnants and pearls in the secondary palate in the human abortus: a contribution to the study of the mechanism of cleft palate formation. Cleft Palate J3:240-257.

KITAMURA H. (1991). Evidence for cleft palate as a postfusion phenomenon. Cleft Palate Craniofac J28:195-210.

LEVINSON H, PELED Z, LIU W, LONGAKER MT, ALLISON GM, EHRLICH HP. (2001). Fetal rat amniotic fluid: transforming growth factor beta and fibroblast collagen lattice contraction. J Surg Res 100:205-210.

MACKOOL RJ, GITTES GK, LONGAKER MT. (1998). Scarless healing. The fetal wound. Clin Plast Surg 25:357-365.

MAST BA, DIEGELMANN RF, KRUMMEL TM, COHEN IK. (1992). Scarless wound healing in the mammalian fetus. Surg Gynecol Obstet 174:441-451.

MIETTINEN PJ, CHIN JR, SHUM L, SLAVKIN HC, SHULER HC, DERYNCK R, WERB Z. (1999). Epidermal growth factor receptor function is necessary for normal craniofacial development and palate closure. Nature Genet. 22:69-73.

MULVIHILL SJ, STONE MM, DEBAS HT, FONKALSRUD EW. (1985). The role of amniotic fluid in fetal nutrition. J Pediatr Surg 20:668-672.

MULVIHILL SJ, STONE MM, FONKALSRUD EW, DEBAS HT. (1986). Trophic effect of amniotic fluid on fetal gastrointestinal development. JSurg Res 40:291 296.

NANDA R, MAY DL, LITE S. (1977). The role of amniotic fluid on the in-vitro palatal fusion of normal and vitamin A-treated rat foetuses. Arch Oral Bio/22:613-618.

ÖZGENEL GY, SAMLI B, OZCAN M. (2001). Effects of human amniotic fluid on peritendinous adhesion formation and tendon healing after flexor tendon surgery in rabbits. J Hand Surg 26:332-339.

POURTOIS M. (1968). Amniotic fluid and palatal fusion in the rat. Arch Oral Biol 13:87-92.

PROETZEL G, PAWLOWSKI SA, WILES MV, YIN M, BOIVIN GP, HOWLES PN, DING J, FERGUSON MW, DOETSCHMAN T. (1995). Transforming growth factor-beta 3 is required for secondary palate fusion. Nat Genet 11:409-414.

REICH H, TRITCHLER D, HERZENBERG AM, KASSIRI Z, ZHOU X, GAO W, SCHOLEY JW. (2005). Albumin activates ERK via EGF receptor in human renal epithelial cells. J Am Soc Nephro/16:1266-1278.

SANCHO MA, JULIA V, ALBERT A, DIAZ F, MORALES L. (1997). Effect of the environment on fetal skin wound healing. J Pediatr Surg 32:663-666.

SHIOTA K, FUJITA S, AKIYAMA T, MORI C. (1990a). Expression of the epidermal growth factor receptor in developing fetal mouse palates: an immunohistochemical study. Am J Anat 188:401-408.

SHIOTA K, KOSAZUMA T, KLUG S, NEUBERT D. (1990b). Development of the fetal mouse palate in suspension organ culture. Acta Anat (Basel) 137:59-64.

SIBILIA M, WAGNER E. (1995). Strain-dependent epithelial defects in mice lacking the EGF receptor. Science 269:234-238.

SPERBER GH, MACHIN GA. (1994). The enigma of cephalogenesis. Cleft Palate
Craniofac $\sqrt{ } 31: 91-96$

STARK RB, EHRMANN NA. (1958). The development of the center of the face with particular reference to surgical correction of bilateral cleft lip. Plast Reconstr Surg 21:177-192.

SUNDELL HW, GRAY ME, SERENIUS FS, ESCOBEDO MB, STAHLMAN MT. (1980). Effects of epidermal growth factor on lung maturation in fetal lambs. $\mathrm{Am}$ $J$ Patho/ 100:707-725.

TAKIGAWA T, SHIOTA K. (2004). Terminal differentiation of palatal medial edge epithelial cells in vitro is not necessarily dependent on palatal shelf contact and midline epithelial seam formation. Int J Dev Bio/48:307-317. (http://dx.doi.org/ $10.1387 / \mathrm{ijdb} .041840 \mathrm{tt}$ )

TAMMI R, PASONEN-SEPPANEN S, KOLEHMAINEN E, TAMMI M. (2005). Hyaluronan synthase induction and hyaluronan accumulation in mouse epidermis following skin injury. $J$ Invest Dermato/124:898-905.

TAYA Y, O'KANE S, FERGUSON MW. (1999). Pathogenesis of cleft palate in TGFbeta3 knockout mice. Development 126:3869-3879.

THREADGILL DW, DLUGOSZ AA, HANSEN LA, TENNENBAUM T, LICHTIU, YEE D, LAMANTIA C, MOURTON T, HERRUP K, HARRIS RC, BARNARD JA, YUSPA SH, COFFEY RJ, MAGNUSON T. (1995). Targeted disruption of mouse EGF receptor: effect of genetic background on mutant phenotype. Science 269:230-234.

VARNER MW, DILDY GA, HUNTER C, DUDLEY DJ, CLARK SL, MITCHELL MD. (1996). Amniotic fluid epidermal growth factor levels in normal and abnormal pregnancies. J Soc Gynecol Investig 3:17-19.

VAZIRI SANI F, HALLBERG K, HARFE BD, MCMAHON AP, LINDE A, GRITLILINDE A. (2005). Fate-mapping of the epithelial seam during palatal fusion rules out epithelial-mesenchymal transformation. Dev Bio/285:490-495.

WHITBY DJ, FERGUSON MW. (1991). The extracellular matrix of lip wounds in fetal, neonatal and adult mice. Development 112:651-668.

YAMAMOTO T, CUI XM, SHULER CF. (2003). Role of ERK1/2 signaling during EGF-induced inhibition of palatal fusion. Dev Bio/260:512-521.

YOSHIMURA S, MASUZAKI H, MIURA K, GOTOH H, MORIYAMA S, FUJISHITA A, ISHIMARU T.(2000). Effect of epidermal growth factor on lung growth in experimental fetal pulmonary hypoplasia. Early Hum Dev 57:61-69.

XU X., HAN J., ITO Y., BRINGAS JR. P., URATA MM., CHAI Y. (2006). Cell autonomous requirement for Tgfbr2 in the disappearance of medial edge epithelium during palatal fusion. Dev Bio/277: 238-248.

Received: 13th January 2006 Reviewed by Referees: 22nd February 2006 Modified by Authors and Accepted for Publication: 15th August 2006 Published Online: 17 November 2006 Edited by: Makoto Asashima 